Article

\title{
Novel Nanohybrids Based on Supramolecular Assemblies of Meso-tetrakis-(4-sulfonatophenyl) Porphyrin J-aggregates and Amine-Functionalized Carbon Nanotubes
}

\author{
Mariachiara Trapani ${ }^{1}\left(\mathbb{D}\right.$, Antonino Mazzaglia $1, * \mathbb{C}$, Anna Piperno ${ }^{2,3} \mathbb{C}^{1}$, Annalaura Cordaro ${ }^{1,2}$, \\ Roberto Zagami ${ }^{1}$, Maria Angela Castriciano ${ }^{1, *} \mathbb{( D}$, Andrea Romeo ${ }^{1,2,4} \mathbb{D}$ and \\ Luigi Monsù Scolaro 1,2,4 \\ 1 CNR-ISMN, Istituto per lo Studio dei Materiali Nanostrutturati c/o Dipartimento di Scienze Chimiche, \\ Biologiche, Farmaceutiche ed Ambientali, Università di Messina, V. le F. Stagno D’Alcontres 31, 98166 \\ Messina, Italy; mariachiara.trapani@cnr.it (M.T.); annalaura.cordaro@ismn.cnr.it (A.C.); \\ roberto.zagami@ismn.cnr.it (R.Z.); anromeo@unime.it (A.R.); lmonsu@unime.it (L.M.S.) \\ 2 Dipartimento di Scienze Chimiche, Biologiche, Farmaceutiche ed Ambientali, Università di Messina, \\ V. le F. Stagno D'Alcontres 31, 98166 Messina, Italy; apiperno@unime.it \\ 3 Consorzio Interuniversitario Nazionale di Ricerca in Metodologie e Processi Innovativi di Sintesi, \\ C.I.N.M.P.I.S., Unità Operativa dell'Università di Messina, V. le F. Stagno D'Alcontres, 3198166 Messina, Italy \\ 4 Consorzio Interuniversitario di Ricerca in Chimica dei Metalli nei Sistemi Biologici, C.I.R.C.M.S.B, \\ Unità Operativa dell'Università di Messina, V. le F. Stagno D'Alcontres, 31, 98166 Messina, Italy \\ * Correspondence: antonino.mazzaglia@cnr.it (A.M.); maria.castriciano@cnr.it (M.A.C.)
}

Received: 13 February 2020; Accepted: 26 March 2020; Published: 2 April 2020

\begin{abstract}
The ability of multiwalled carbon nanotubes (MWCNTs) covalently functionalized with polyamine chains of different length (ethylenediamine, EDA and tetraethylenepentamine, EPA) to induce the J-aggregation of meso-tetrakis(4-sulfonatophenyl)porphyrin (TPPS) was investigated in different experimental conditions. Under mild acidic conditions, protonated amino groups allow for the assembly by electrostatic interaction with the diacid form of TPPS, leading to hybrid nanomaterials. The presence of only one pendant amino group for a chain in EDA does not lead to any aggregation, whereas EPA (with four amine groups for chain) is effective in inducing J-aggregation using different mixing protocols. These nanohybrids have been characterized through UV/Vis extinction, fluorescence emission, resonance light scattering and circular dichroism spectroscopy. Their morphology and chemical composition have been elucidated through transmission electron microscopy (TEM) and scanning transmission electron microscopy (STEM). TEM and STEM analysis evidence single or bundles of MWCNTs in contact with TPPS J-aggregates nanotubes. The nanohybrids are quite stable for days, even in aqueous solutions mimicking physiological medium $(\mathrm{NaCl} 0.15 \mathrm{M})$. This property, together with their peculiar optical features in the therapeutic window of visible spectrum, make them potentially useful for biomedical applications.
\end{abstract}

Keywords: porphyrin; J-aggregates; carbon nanotubes; nanohybrids

\section{Introduction}

Carbon nanotubes (CNTs) are intriguing materials with applications ranging from nanotechnology-related devices (i.e., in electronics, energy storage, water treatment, as sensor/biosensor) [1] to drug/probes delivery systems for therapy and diagnosis [2,3].

Functionalized CNTs are widely used to reduce the intrinsic toxicity of "as produced" (pristine) CNTs by increasing the tolerability and the biodegradability in vivo $[4,5]$. Furthermore, opportunely 
modified and sized multiwalled CNTs (MWCNTs) are not retained in the organs and can be easily cleared by body excretion [6].

Functional nanomaterials based on CNTs were designed as therapeutic enhancers by combining CNTs with different systems, such as cyclodextrins, biomolecules or porphyrinoids [3]. Recently, some of us reported antiviral- and plasmid/delivery systems [7,8] based on properly functionalized MWCNTs, investigating also their intracellular fate. Similarly to other nanomaterials based on carbon for multi-targeted therapies and imaging [9,10], CNTs functional nanomaterials were endowed with unique properties generated by the synergic actions of components [3].

Non-covalent modification of CNTs with porphyrinoids is a well-investigated strategy to modulate the environment of chromophores, thus improving the light absorption and emission features [11], charge-transport [12] or energy transfer properties [13] in view of bio-labeling and light harvesting applications. In particular, it is well-known as $\pi$-stacking of CNTs with hydrosoluble porphyrins provides donor-acceptor complexes with efficient energy transfer [14]. Porphyrin free bases or metallo porphyrins/DNA supramolecular systems undergo strong charge transfer with semiconducting CNTs [15]. Enhanced photoconductivity has been reported for J- and H- porphyrin aggregates (head-to-tail or head-to-head molecules stacking, respectively) obtained in solution by interaction with single-walled CNTs (SWCNTs) [16] or at solid state with double-walled CNTs (DWCNTs) [17] or by decorating MWCNTs film [18]. Moreover, recently it was demonstrated that photoluminescence properties of a hybrid material assembled by formation of J-aggregates of benzo[e]indocarbocyanine (BIC) on SWCNTs can be modulated by selecting cis- or trans- isomer of the dye: the first one quenches the photoluminescence by strong interaction with CNTs, whereas the second one forms free J-aggregates characterized by photoluminescence bands of practical use in biomedical imaging [19]. Indeed, it is well known that J-aggregates feature very narrow red-shifted absorption bands, showing renewed optical, photophysical, and structural properties vs. monomer [20]. In this framework, multifunctional nanotheranostic based on J-type aggregates of cyanine [21,22], bacterio-pheophorbide [23], chlorine [24], and Bodipy [25] were proposed due to their excellent photothermal and/or NIR absorbing features for applications in imaging guided therapy (i.e., photoacustic imaging). However, these J-type aggregates generally need to be entrapped in liposomes or dispersed in surfactants to increase their solubility and bio-availability.

Within the incoming research of composite nanomaterials, our interest has been addressed to J-aggregates of meso-tetrakis-(4-sulfonatophenyl)porphyrin (TPPS) exhibiting peculiar optical features [26-29]. Such features can be fine-tuned depending on the strategy adopted to obtain the structure, i.e., by selecting appropriate polyamines as scaffolds [30-35] or by tailoring nanomaterials (i.e., metal nanoparticles) [36-40] or triggering porphyrin J-aggregation by modulating $\mathrm{pH}$ and/or ionic strength [41-44]. TPPS J-aggregates, in line of principle, would not necessitate further manipulation/encapsulation to explicate their properties within cells or tissues. These aggregated species could lead to stimuli-responsive therapeutic action upon irradiation on their extinction bands, fluorescence probing in cellular environments, or refilling of the dye upon eventual J-aggregates disassembly [45,46] in biological sites [47].

Regarding the design of SWCNTs/TPPS nanohybrids, assembly between TPPS with amine-conjugated SWCNTs has been obtained in water, pointing out that the photophysical properties of porphyrin are largely influenced by length of CNTs amine chain [48] whereas TPPS J-aggregates on SWCNTs have been prepared in organic solvents [49].

Herein, we report on the formation of relatively stable TPPS J-aggregates wrapped to covalently amine-modified MWCNTs in aqueous solution. We anticipate that, in the presence of tetraethylenepentamine-functionalized MWCNTs (MWCNT-EPA) in mild acidic conditions, TPPS porphyrin easily self-assembles into J-aggregates exhibiting peculiar extinction bands in the visible region (i.e., $\cong 493 \mathrm{~nm}$ ) and in the therapeutic window (i.e., $\cong 710 \mathrm{~nm}$ ), together with an emission band in the red spectral region for potential phototherapeutic and/or photodiagnostic applications. Conversely, ethylenediamine-modified MWCNTs (MWCNT-EDA) do not induce J-aggregate formation due to 
EDA structural features vs. EPA ones. The MWCNT-EPA/TPPS J-aggregates are stable in mimicking physiological medium $(\mathrm{NaCl}=0.15 \mathrm{M})$, thus opening the route for their potential application in dual therapeutic/diagnostic assessment.

\section{Materials and Methods}

The 5,10,15,20-tetrakis(4 sulfonatophenyl)porphyrin (TPPS), MWCNTs, tert-butyl 2-aminoethylcarbamate (EDABoc), tetraethylenepentamine (EPA), $\mathrm{N}$-(3-dimethylaminopropyl)-N'-ethylcarbodiimide hydrochloride (EDC), 1-Hydroxybenzotriazole (HOBt), Ninhydrin test kit, other solvents and reagents were purchased from Sigma-Aldrich Chemicals (Milan, Italy). The stock porphyrin aqueous solutions were freshly prepared and their concentrations were determined using the extinction coefficient at the Soret maximum $\left(\varepsilon=5.33 \times 10^{5} \mathrm{M}^{-1} \mathrm{~cm}^{-1}\right.$ at $\lambda=414 \mathrm{~nm})$. All the reagents were used without further purification and all the solutions were prepared in dust free Milli-Q water (Merck, Darmstadt, Germany).

Carboxylated multiwalled carbon nanotubes (MWCNT-Ox) were prepared by the oxidation of MWCNTs (mean diameter 5-10 nm; average length 10-20 $\mu \mathrm{m}$ ) with sulfuric acid/nitric acid (3:1 v/v, $98 \%$ and 69\%) according to the protocol previously reported [50]. MWCNT-Ox (100 mg) in $25 \mathrm{~mL}$ of dry DMF were sonicated for $30 \mathrm{~min}$, then EDC (112 mg, $0.58 \mathrm{mmol})$ and HOBt (40 mg, $0.30 \mathrm{mmol})$, were added and the black suspension was stirred at room temperature for one hour. EDABoc (55 mg, $0.24 \mathrm{mmol}$ ) was added and the reaction was stirred for 72 hours. Water/ethanol (1:1 mixture) was added and the crude reaction mixture was filtered under vacuum (Millipore, $0.1 \mu \mathrm{m}$ ), washed with an excess of water/ethanol and finally diethyl ether. The resulting MWCNT-EDABoc were dispersed in dioxane $(10 \mathrm{~mL})$ and treated with $5 \mathrm{~mL}$ of $\mathrm{HCl} 4 \mathrm{M}$ at room temperature for $4 \mathrm{~h}$. The mixture was filtered under vacuum (Millipore, $0.1 \mu \mathrm{m}$ ) and the precipitate was treated with $5 \mathrm{~mL}$ of triethylamine/water (1:4), thus obtaining MWCNT-EDA. This was washed several times with water/ethanol by successive bath sonication and centrifugation $(8000 \mathrm{rpm} 10 \mathrm{~min})$ procedures and finally dried at $60{ }^{\circ} \mathrm{C}$ to give $60 \mathrm{mg}$ of material. The amount of free amine groups on MWCNT-EDA was estimated by Kaiser test (0.22 mmol/g).

MWCNT-EPA were prepared by the coupling of MWCNT-Ox and EPA, in presence of EDC/HOBt, according to the amidation reaction procedure above described. The resulting MWCNT-EPA were washed several times with water/ethanol by successive bath sonication and centrifugation (8000 rpm $10 \mathrm{~min}$ ) procedures and finally dried at $60{ }^{\circ} \mathrm{C}$. Termogravimetric analysis (TGA) data indicated a weight loss of about $4.3 \%$ at $500{ }^{\circ} \mathrm{C}$, which roughly corresponds to $0.22 \mathrm{mmol} / \mathrm{g}$ of EPA. The ninhydrin assay indicated an amount of free amino groups of $0.44 \mathrm{mmol} / \mathrm{g}$.

Primary amine loadings were measured spectroscopically using the colorimetric Kaiser conditions [51,52]. Commercial Kaiser test kit is composed of three solutions as it follows: (a) $0.5 \mathrm{~g} / \mathrm{mL}$ of phenol in absolute EtOH; (b) $2 \mathrm{~mL}$ of potassium cyanide $1 \mathrm{mM}$ (aqueous solution) dissolved in $98 \mathrm{~mL}$ of pyridine; (c) $0.05 \mathrm{~g} / \mathrm{mL}$ of ninhydrin in absolute EtOH. Briefly, $0.5 \mathrm{mg}$ of MWCNT-EDA or MWCNT-EPA were treated in sequence with $75 \mu \mathrm{L}$ of solution (a), $100 \mu \mathrm{L}$ of solution (b) and $75 \mu \mathrm{L}$ of solution (c). The dispersion was sonicated in a water bath and then was heated at $120{ }^{\circ} \mathrm{C}$ for $5 \mathrm{~min}$, diluted with $4750 \mu \mathrm{L}$ of absolute $\mathrm{EtOH}$ and centrifugated at 14,000 rpm. The absorbance at $570 \mathrm{~nm}$ of supernatant was correlated to the amount of free amine groups on MWCNTs surface $\left(\mathrm{NH}_{2}\right.$ loading (mmol/g)); using the following equation:

$$
[\text { free amines }]=([\text { Abs }] \times \text { dilution } \times 1000) /(\varepsilon \times \text { sample weight } \times \text { optical path })
$$

where dilution was fixed to $5 \mathrm{~mL}$, optical path was $1 \mathrm{~cm}$; sample weight was $0.5 \mathrm{mg}$; extinction coefficient $(\varepsilon)$ was $15,000 \mathrm{M}^{-1} \mathrm{~cm}^{-1}$.

Dispersions of MWCNT-EDA and MWCNT-EPA $(0.43 \mathrm{mg} / \mathrm{mL})$ were prepared in $10 \mathrm{mM}$ citrate buffer by bath sonication for $20 \mathrm{~min}$. For the experiments, a volume of $100 \mu \mathrm{L}$ has been used and diluted to a final concentration of $0.02 \mathrm{mg} / \mathrm{mL}$. The interaction of TPPS with the two batches of MWCNTs 
has been investigated in citrate buffer solution $(10 \mathrm{mM}, \mathrm{pH} 2.4)$ following two different mixing order procedures: (i) porphyrin-first protocol (PF) and (ii) porphyrin- last protocol (PL), consisting of the addition of a proper volume of MWCNTs dispersion to a diluted TPPS solution in citrate buffer and of the addition of TPPS from a stock solution to a diluted MWCNTs dispersion, respectively [43,53]. In some experiments MWCNT- EPA in citrate buffer has been previously mixed with $\mathrm{NaCl}(0.15 \mathrm{M})$, followed by the addition of TPPS. In all the experiments, the final concentration of TPPS was $5 \mu \mathrm{M}$.

UV-Vis spectra have been collected on a diode-array spectrophotometer Agilent model 8452. The circular dichroism (CD) spectra were recorded on a JASCO J-720 spectropolarimeter, equipped with a $450 \mathrm{~W}$ xenon lamp. CD spectra were corrected both for the cell and buffer contributions. A Jasco mod. FP-750 spectrofluorometer has been used to record fluorescence emission and Resonance Light Scattering (RLS) spectra. Emission spectra were not corrected for the absorption of the samples and a synchronous scan protocol with a right angle geometry was adopted for collecting RLS spectra [54]. All the aqueous dispersions were analysed by using a $1 \mathrm{~cm}$ optical path cuvette.

TGA was performed by using PerkinElmer Instruments Pyris1 TGA at a heating rate of $10^{\circ} \mathrm{C} / \mathrm{min}$ over the range from room temperature (r.t) to $1000{ }^{\circ} \mathrm{C}$ under $\mathrm{N}_{2}$ atmosphere.

A TEM, JEM2100 LaB, working at $100 \mathrm{kV}$, and a digital Scanning transmission electron microscopy (STEM) set with BF \& DF STEM Detectors plus SE/BSE detector (University of Exeter, UK) were used to investigate morphology of MWCNTs and MWCNTs/TPPS J-aggregates. Samples were prepared by evaporating ten drops of the aqueous dispersions of the investigated system more days after mixing (1-3 days) on 300 mesh holey-carbon coated copper grids.

\section{Results and Discussion}

\section{Synthesis and Characterization of Amine Multiwalled Carbon Nanotubes}

Amine multiwalled carbon nanotubes, MWCNT-EDA and MWCNT-EPA, were prepared by coupling of carboxylated MWCNTs (MWCNT-Ox) with tert-butyl 2-aminoethylcarbamate (EDABoc) or tetraethylenepentamine using EDC/HOBt in DMF according to Figure $1 \mathrm{~A}, \mathrm{~B}$, respectively. MWCNT-Ox were prepared by the oxidation $\left(\mathrm{HNO}_{3} / \mathrm{H}_{2} \mathrm{SO}_{4} 1: 3,6 \mathrm{~h}, 60^{\circ} \mathrm{C}\right)$ of commercially available multiwalled carbon nanotubes according to a previously reported procedure $[8,50]$.

A)

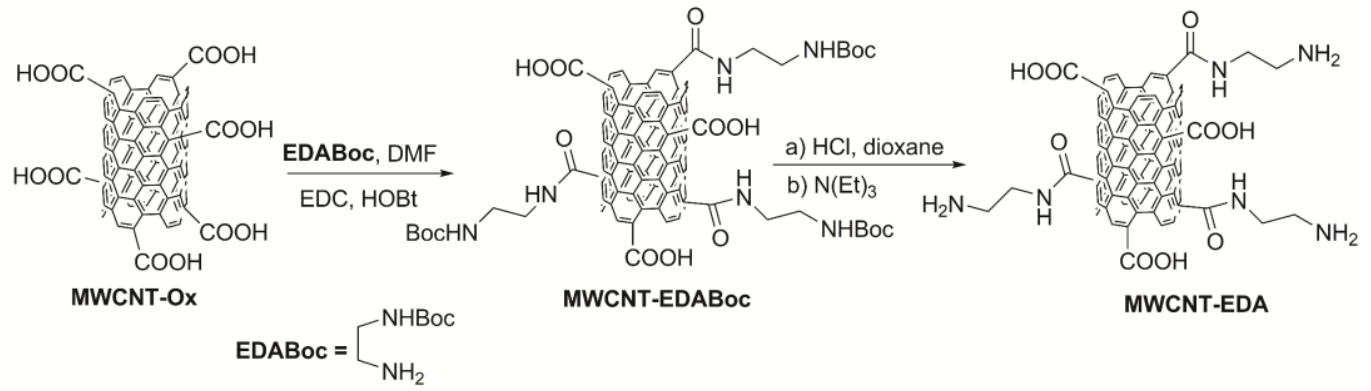

B)

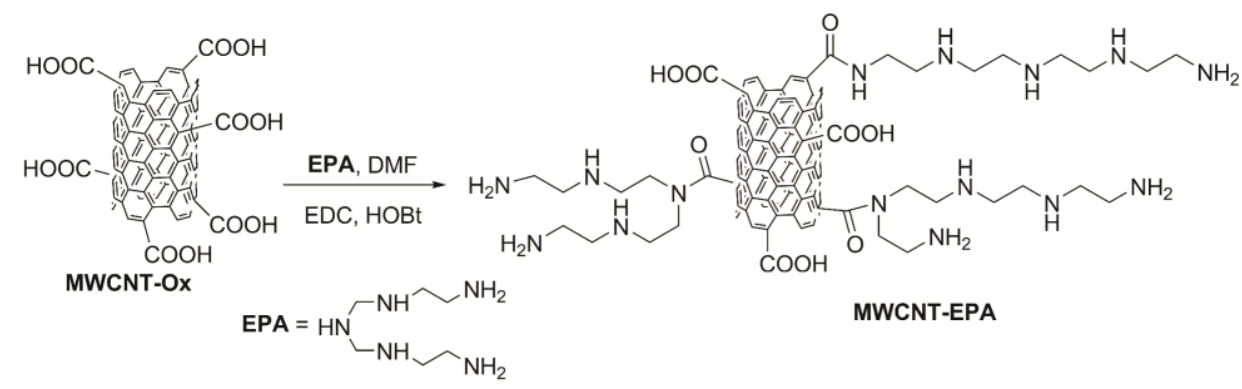

Figure 1. Schematic representations of MWCNT-EDA (A) and MWCNT-EPA (B) synthetic procedures. 
The degree of functionalization of MWCNTs was investigated by TGA analysis (Figure 2) and the primary amines loadings was determined using the colorimetric Kaiser test [51,52].
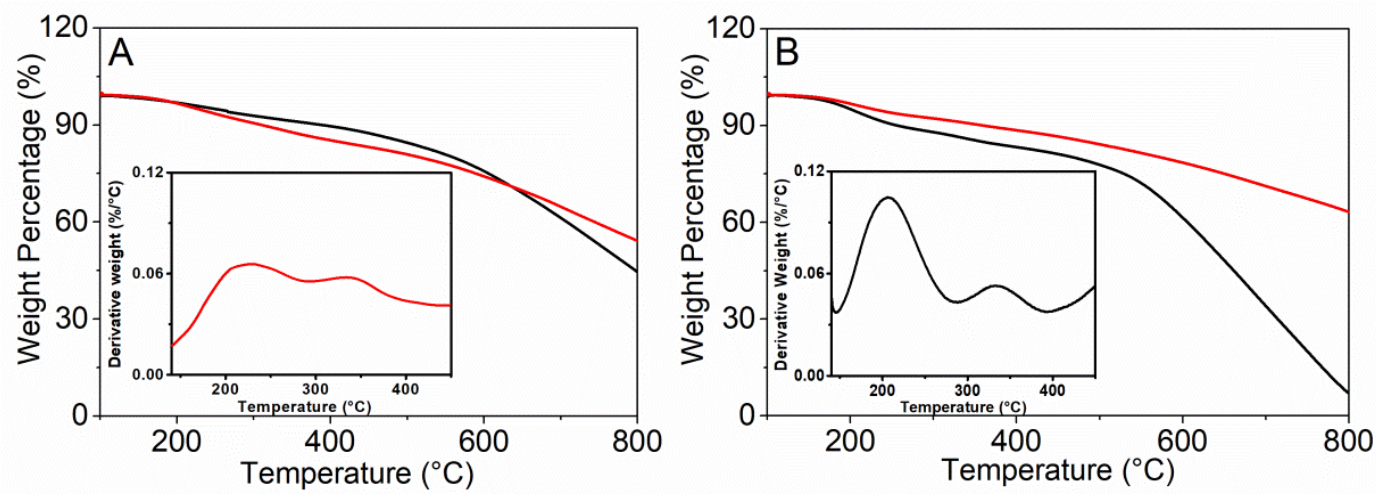

Figure 2. TGA profiles of MWCNT-Ox (dark line) and MWCNT-EPA (red line) (A). TGA profiles of MWCNT-EDABoc (dark line) and MWCNT-EDA (red line) (B). In the insets DTG curve of MWCNT-EPA (A) and MWCNT-EDABoc (B). TGA analyses were carried out under $\mathrm{N}_{2}$ atmosphere.

The TGA curve of MWCNT-Ox shows a gradual weight loss of about $15.5 \%$ at $500{ }^{\circ} \mathrm{C}$ (Figure $2 \mathrm{~A}$ ). MWCNT-EPA TGA profile displays two weight loss steps in the range $100-400{ }^{\circ} \mathrm{C}$, likely due to decomposition of polyamine alkyl chain (inset of Figure 2A). From TGA data, a weight loss of about $4.3 \%$ at $500{ }^{\circ} \mathrm{C}$ which roughly corresponds to $0.22 \mathrm{mmol} / \mathrm{g}$ of EPA (Figure 2A) has been estimated. By the correlation with the absorbance at $570 \mathrm{~nm}$ using the ninhydrin assay, an amount of free amino groups of $0.44 \mathrm{mmol} / \mathrm{g}$ has been determinated, probably suggesting a role of secondary amine groups in the amidation reactions (Figure 1B).

According to literature data, a higher thermal stability of MWCNTs containing free amine groups has been detected with respect to the MWCNTs sample containing Boc-amine groups (MWCNT-EDA vs. MWCNT-EDABoc, Figure 2B) $[55,56]$. The significant weight loss of MWCNT-EDABoc in the range $100-300{ }^{\circ} \mathrm{C}$ (see DTG, inset Figure $2 \mathrm{~B}$ ) can be attributed to the thermal decomposition and rearrangement of the tert-butoxyl groups. On the basis of TGA data, it was not realistic to determine the degree of functionalization in terms of weight loss $(\Delta \mathrm{m} \approx 0.9-1 \%)$ [57]. Thus, we have estimated the amount of free amine functional groups by the Kaiser test $(0.22 \mathrm{mmol} / \mathrm{g})$.

TEM analyses of functionalized MWCNTs indicated that the chemical functionalization with amine groups preserved the characteristic morphology of multiwalled tubes scaffold. An average external diameter of $\sim 10 \mathrm{~nm}$, corresponding to an average number of 8-10 layers were found. MWCNT-ox appeared strongly aggregates in bundles (Figure 3A), whereas well distinct isolated MWCNTs are observed in TEM image of amine functionalized MWCNTs (MWCNT-EDA, Figure 3B and MWCNT-EPA, Figure 3C). Moreover, all the functionalized MWCNTs (MWCNT-Ox, MWCNT-EPA and MWCNT-EDA) were shortened by oxidation: the length was reduced from the micrometre (pristine MWCNTs, see Supplementary Figure S1) to nanometre scale [8,50].
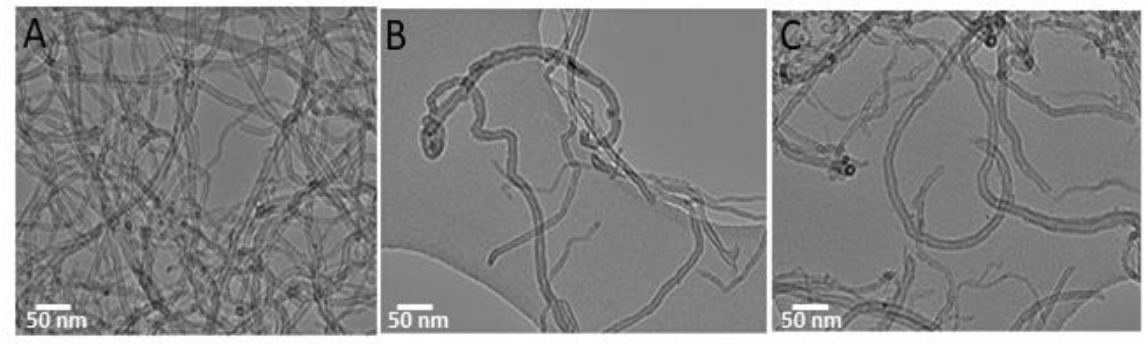

Figure 3. TEM images of MWCNT-Ox (A), MWCNT- EDA (B) and MWCNT-EPA (C). 
In order to obtain MWCNT-EDA/TPPS J-aggregates hybrids, the two aforementioned mixing order protocols (both PF and PL) have been used under mild acidic condition. Whatever of the procedure employed, we found that the extinction features of free diacid porphyrin (B band centered at $434 \mathrm{~nm}$ and $Q$ bands at 592 and $645 \mathrm{~nm}$ ) remained unchanged even after 1 day (Figure 4A). No TPPS J aggregates were formed and no interaction between TPPS and MWCNT-EDA was revealed. This behavior could be ascribable to the presence of only one pendant amino group for chain in EDA, and this observation agrees with previous results on the role of the amine chain length in inducing the aggregation of TPPS [53].
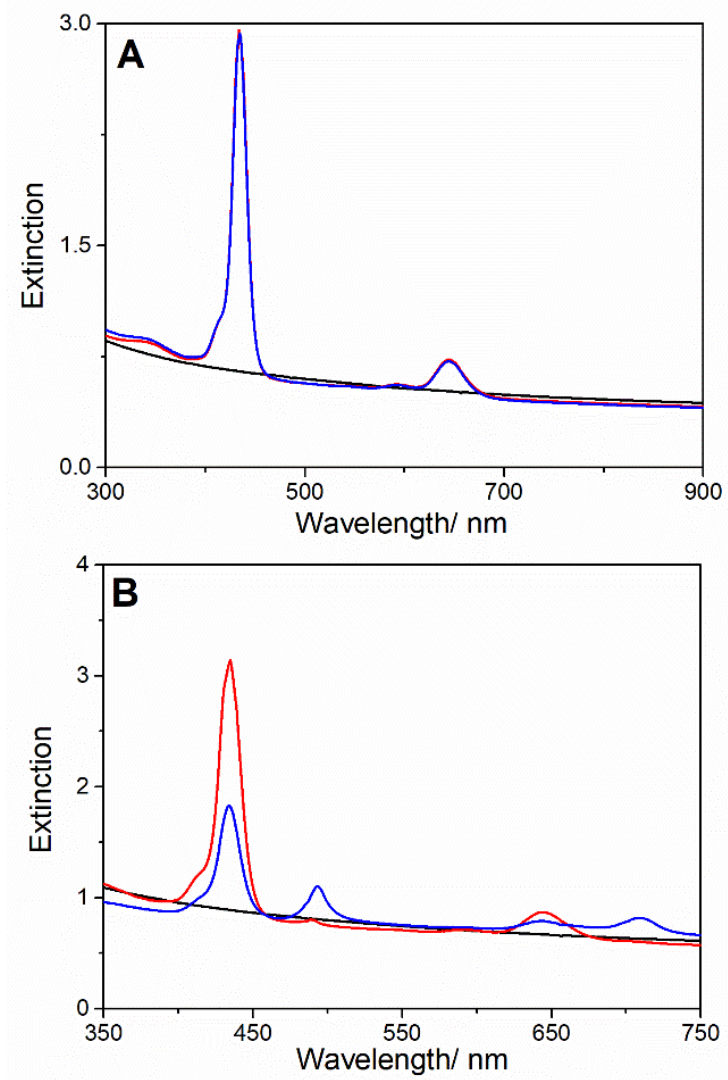

Figure 4. UV-Vis spectra of MWCNT-EDA (black line) and upon TPPS addition (red line), and 1 day after mixing (blue line) (A), and of MWCNT-EPA (black line), upon TPPS addition (red line), and 1 day after mixing (blue line) (B). Experimental conditions: [TPPS] $=5 \mu \mathrm{M}$; MWCNT-EDA or MWCNT-EPA $=0.02 \mathrm{mg} / \mathrm{mL} ; 10 \mathrm{mM}$ citrate buffer at $\mathrm{pH} 2.4 ; \mathrm{PL}$ protocol; $\mathrm{T}=298 \mathrm{~K}$.

On the other hand, upon the addition of the porphyrin to the MWCNT-EPA dispersion, the UV-Vis profile shows the spectral signatures both of the diacid form of TPPS (B-band at $434 \mathrm{~nm}$ ) and of J-aggregates evidenced by their typical extinction band arising at $489 \mathrm{~nm}$. During the time, we observed the decrease of the intensity of the diacid band accompanied by the increase of the intensity of J-band, which furthermore undergoes a bathochromic shift from 489 to $493 \mathrm{~nm}$. After one day, at the end of the aggregation process, UV-Vis spectrum of MWCNT-EPA/TPPS exhibits the B and Q bands ascribable to the residual monomeric diacid form of TPPS and J-aggregates (Figure 4B). It is noteworthy that the formation of J-aggregates does not occur under the same experimental conditions in absence of MWCNT-EPA, but it can be forced by decreasing the $\mathrm{pH}$ of the medium [42]. On the bases of the experimental evidences, we suggest that only EPA functionalized MWCNTs are able to trigger the TPPS aggregation process. This could be ascribable to the occurrence of an initial electrostatic interaction among a sufficient number of positively charged protonated amino groups on the CNTs surface and negatively charged sulfonated groups present in the periphery of the dyes [31,58]. Moreover, 
the observed red-shift of the extinction B-band of J-aggregates in the time could suggest a rearrangement of the aggregates due to an interaction with different amine-modified carbon nanotubes or their location in a different microenvironment with respect to the aqueous solution.

The emission spectrum ( $\lambda_{\text {exc }} 455 \mathrm{~nm}$ ), at the end of the aggregation process, shows the typical fluorescence emission of the diacid form of TPPS centered at $669 \mathrm{~nm}$. Further, upon excitation on the J-aggregates band ( $\lambda_{\text {exc }} 493 \mathrm{~nm}$ ), an emission band at $717 \mathrm{~nm}$ can be also detectable (Figure 5). The different ratio of the bands intensity at 669 and $717 \mathrm{~nm}$ at the two distinctive excitation wavelengths is due to the fluorescence emission generated from the aggregated species. This evidence is confirmed by the related excitation spectra (Figure 5 inset) showing spectral features for both the diacidic TPPS and J-aggregates. However, the monomeric porphyrin is the predominant species in the excitation profile at both emission wavelengths, due to its longer lifetime value with respect to the J-aggregate one $[59,60]$.

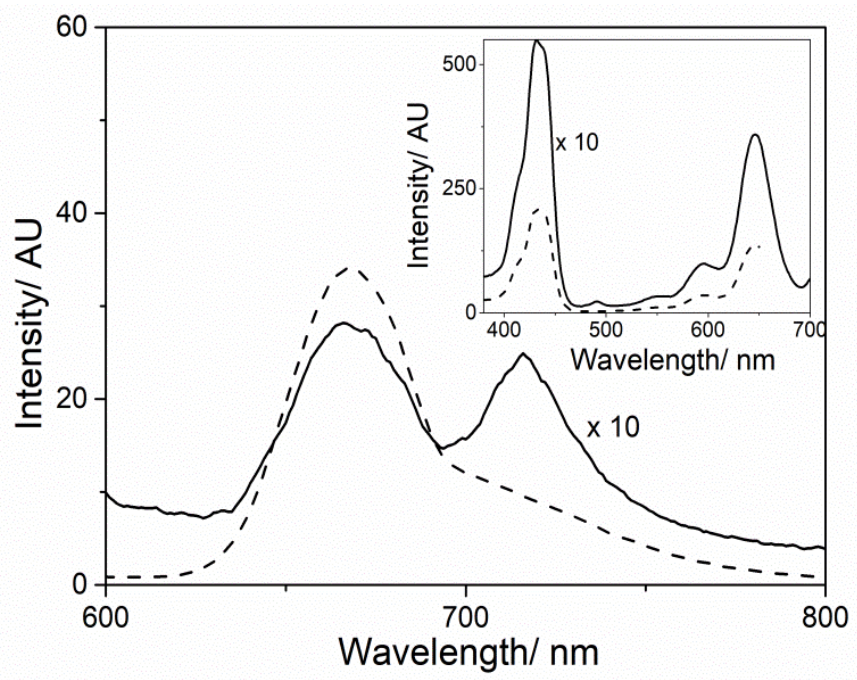

Figure 5. Fluorescence emission spectra of MWCNT-EPA/TPPS J-aggregates system 1 day after mixing (dashed and solid lines recorded at $\lambda_{\text {exc }}=455$ and $493 \mathrm{~nm}$, respectively) and, in the inset, the corresponding excitation spectra (dashed and solid lines recorded at $\lambda_{\mathrm{em}}=669$ and $717 \mathrm{~nm}$, respectively). Experimental conditions: [TPPS] $=5 \mu \mathrm{M}$; MWCNT-EPA $=0.02 \mathrm{mg} / \mathrm{mL} ; 10 \mathrm{mM}$ citrate buffer at $\mathrm{pH} 2.4$; PL protocol; $\mathrm{T}=298 \mathrm{~K}$.

The RLS spectra recorded soon after mixing shows a very sharp peak in the red region of the extinction band which increases in intensity at the end of the aggregation process. These findings agree with our previous results [42], pointing to the formation of self-assemblies of electronically coupled porphyrins, which cause a large enhancement of the resonant light scattering [54] at the red-edge of the extinction peak (Figure 6).

J-aggregates of TPPS induced by MWCNT-EPA were stable in acidic aqueous dispersion for a day or more after preparation. In difference with our previous findings on polyamine-mediated J-aggregates $[30,31,61]$, the optical profiles are in line with the usual Frenkel exciton theory, rather than in terms of an extended network formed by the J-aggregates and amine modified MWCNTs in which dipole-dipole coupling among single porphyrins takes place. 


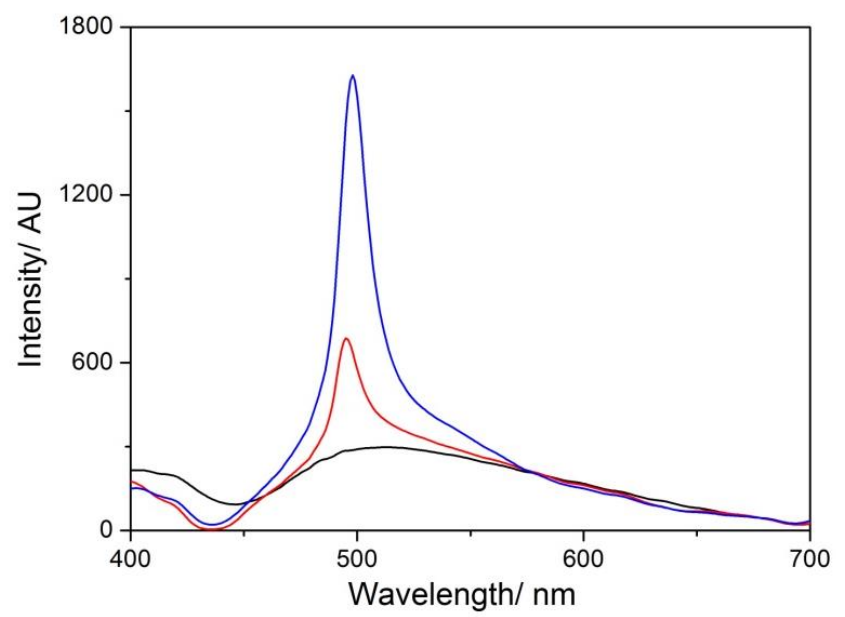

Figure 6. RLS spectra of MWCNT-EPA (black line), after TPPS addition (red line), and 1 day after mixing (blue line). Experimental conditions: [TPPS] $=5 \mu \mathrm{M}$; MWCNT-EPA $=0.02 \mathrm{mg} / \mathrm{mL} ; 10 \mathrm{mM}$ citrate buffer at $\mathrm{pH} 2.4$; PL protocol; $\mathrm{T}=298 \mathrm{~K}$.

CD spectra were recorded after freshly mixing of the components and at the end of the aggregation process (Figure 7). As expected for achiral MWCNT-EPA, CD spectrum is silent before the addition of the chromophoric species, so confirming the absence of optical activity for amine modified CNTs. On the other hand, when TPPS was added a slight bisegnate positive Cotton effect in the aggregates absorption region has been observed. At the end of the aggregation process, an increase in intensity and a red shift of the CD profile were observed. This behavior, observed by means of spectroscopic and light scattering techniques, is due to the formation of large and rearranged structures as the result of the interactions among porphyrin aggregates and functionalized MWCNTs.

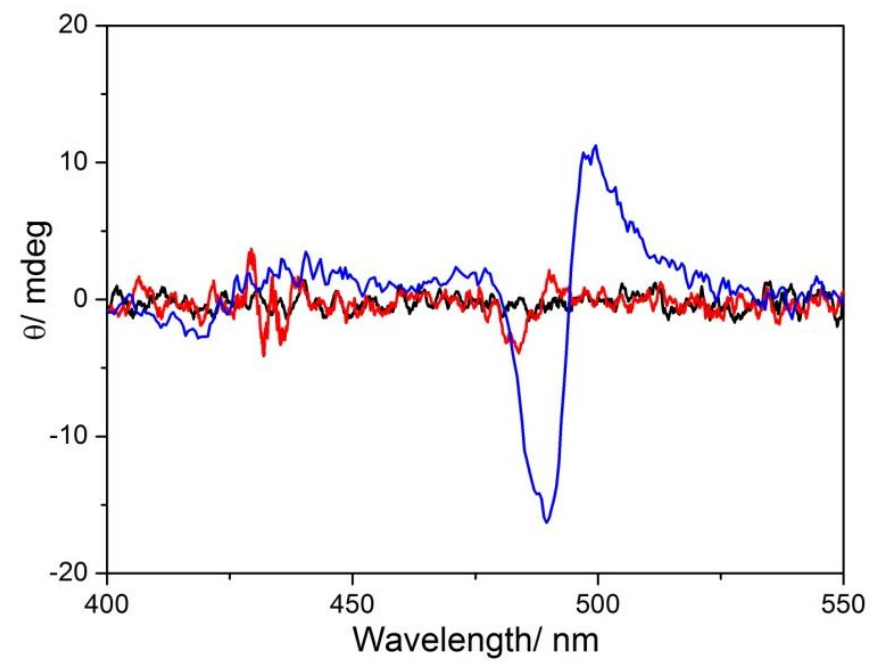

Figure 7. CD spectra of MWCNT-EPA (black line), soon after TPPS addition (red line), and 1 day after mixing (blue line). Experimental conditions: [TPPS] $=5 \mu \mathrm{M} ; \mathrm{MWCNT}-\mathrm{EPA}=0.02 \mathrm{mg} / \mathrm{mL} ; 10 \mathrm{mM}$ citrate buffer at $\mathrm{pH}$ 2.4; PL protocol; $\mathrm{T}=298 \mathrm{~K}$.

In agreement with the spectroscopic characterization, representative TEM images of MWCNT-EPA/TPPS J-aggregates pointed to the coexistence of both MWCNT-EPA and TPPS J-aggregates in the same area (Figure 8 and Supplementary Figure S2). In particular, TPPS J-aggregates with an average diameter of $45 \mathrm{~nm}$ and length of $250-500 \mathrm{~nm}$ seem to be wrapped by separate nanotubes or bundles of MWCNT-EPA having an average external diameter of about $15 \mathrm{~nm}$. 


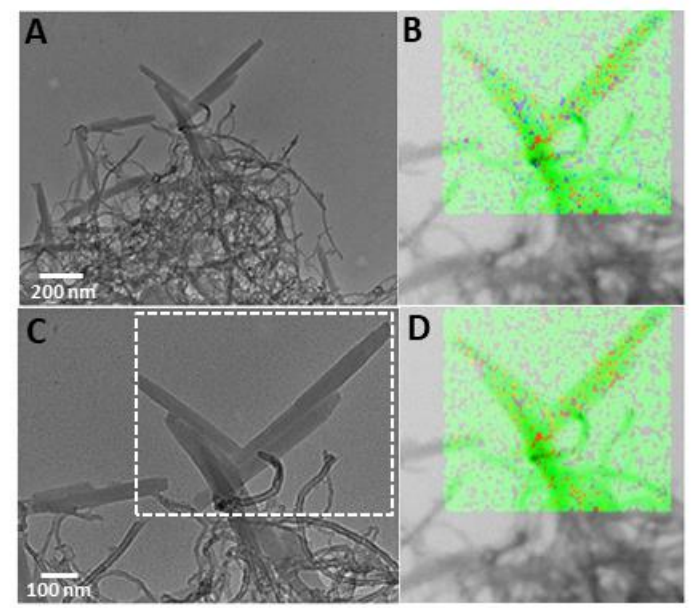

Figure 8. TEM images of MWCNT-EPA/TPPS J-aggregates at low (A) and high resolution (C): (B,D) corresponds to STEM analysis of total $(\mathrm{C} / \mathrm{N} / \mathrm{O} / \mathrm{S})$ and $\mathrm{C} / \mathrm{S}$ merging of elements distribution respectively taken within the dashed region of the assemblies in (C) (for individuals colours of elements refers to (B) in Figure S3; see Materials and Methods for preparation conditions).

STEM analysis of MWCNT-EPA/TPPS J-aggregates shows the total elemental distribution pointing out the presence of carbon and oxygen for MWCNT-EPA, and carbon, oxygen, sulfur and nitrogen for TPPS J-aggregates (Supplementary Figure S3). Interestingly, in the marked area (Figure 8C), the total elements merging (Figure 8B) appears to be similar to the carbon/sulfur merging (Figure 8D). These results evidence the co-localization of TPPS J-aggregates and carbon nanotubes in the investigated samples. Since self-organization phenomenon is a hierarchical process, it is well known as the morphology of final aggregates can be controlled by the mixing order protocol [43]. In this framework, we performed experiments by adding amine carbon nanotubes to diacid TPPS (PF protocol). Surprisingly, at the end of the aggregation process, all the spectroscopic (Supplementary Figures S4 and S5) and morphological features (Supplementary Figure S6) show no change with respect to that observed by previous reagent mixing order protocol (PL). Because, in the case of the self-aggregation of neat TPPS in acidic conditions [43], the mixing order protocol is strictly related to the occurrence of porphyrin nucleation phenomena, here, we are prone to think that MWCNT-EPA could act as nucleation centers, inducing dye aggregation independently by the mixing order protocol.

In order to verify the stability of MWCNT-EPA/TPPS J-aggregates in mimicking physiological medium $(\mathrm{NaCl} 0.9 \% w / w \cong 0.15 \mathrm{M}$ ), the system has been prepared by firstly dispersing MWCNT-EPA in $\mathrm{NaCl} 0.15 \mathrm{M}$ aqueous solution and then adding TPPS. Under these conditions, the spectroscopic evidences of the final system remain almost unchanged (Figure 9) with respect to the unsalted solutions thus confirming the formation of chromophoric assemblies. The premixing of $\mathrm{MWCNTs}$ and $\mathrm{NaCl}$, followed by the addition of porphyrin, seems to lead to a larger amount of J-aggregates due to the ionic strength effect [62]. Generally, optical stability for J-aggregates is difficult to achieve. Therefore, the use of surfactans or the entrapment in liposomes of the dye forming J-aggregates were experienced in literature [21]. In our case, MWCNTs induce, whatever the preparation procedure, the formation of stable J-aggregates able to retain their optical properties even after more days (1-3 days). Therefore, no further manipulation to preserve their pristine optical properties was necessary. 

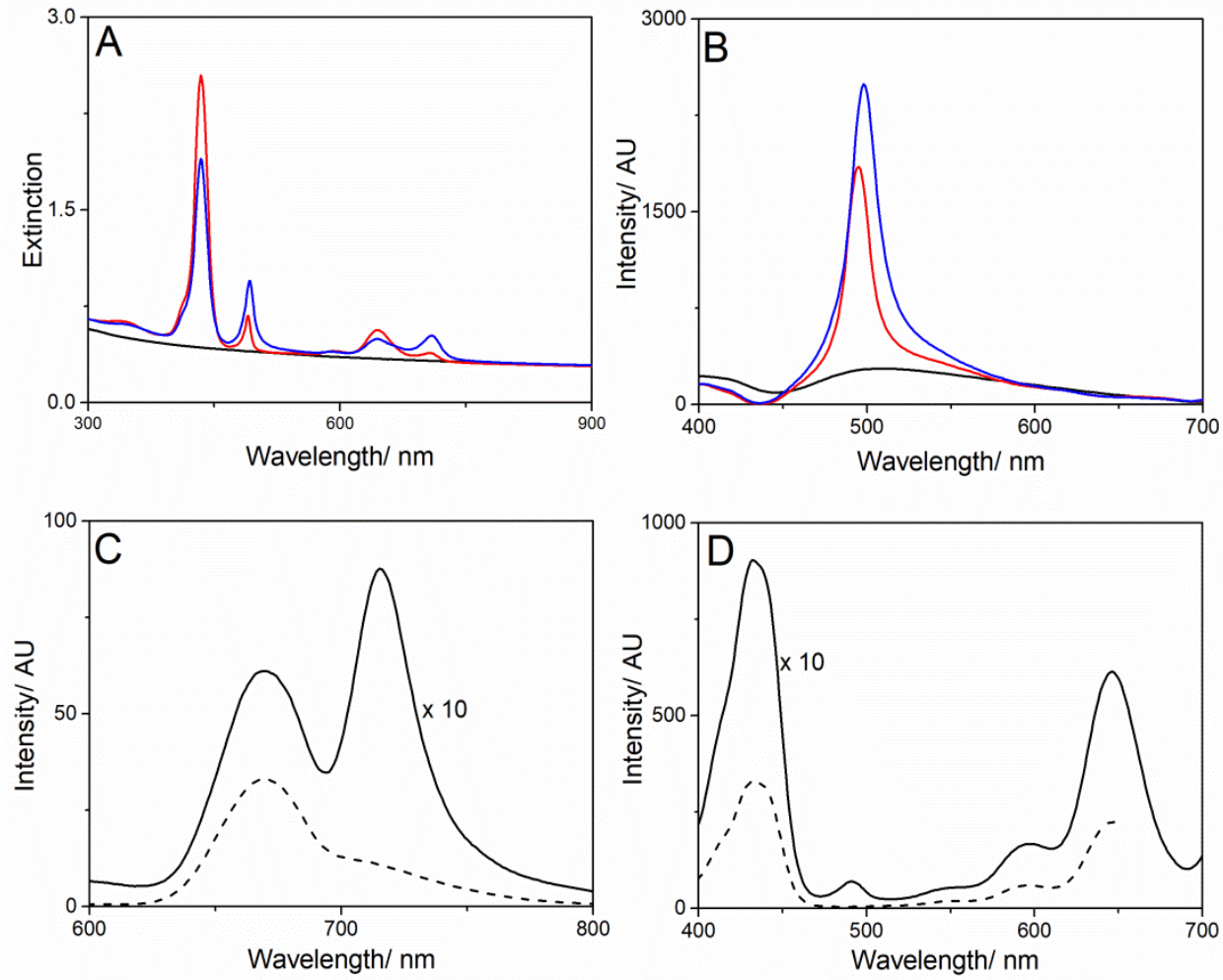

Figure 9. UV- Vis spectra (A) and RLS ( B) of MWCNT-EPA (black line), upon TPPS addition (red line) and $4 \mathrm{~h}$ after mixing (blue line); (C) Fluorescence emission spectra of MWCNT-EPA/TPPS J-aggregates (dashed and solid lines at $\lambda_{\text {exc }}=455$ and $492 \mathrm{~nm}$, respectively) and (D) the corresponding excitation spectrum (dashed and solid lines at $\lambda_{\mathrm{em}}=669$ and and $717 \mathrm{~nm}$, respectively). Experimental conditions: [TPPS $]=5 \mu \mathrm{M} ; \mathrm{MWCNT}-\mathrm{EPA}=0.02 \mathrm{mg} / \mathrm{mL} ; 10 \mathrm{mM}$ citrate buffer at $\mathrm{pH} 2.4 ;[\mathrm{NaCl}]=0.15 \mathrm{M}$, PL protocol; $\mathrm{T}=298 \mathrm{~K}$.

Altogether, the combination of drug carrier ability of MWCNTs with the theranostic properties of porphyrins could allow the development of MWCNTs/TPPS J-aggregates nanohybrids for applications in biomedical field. Unlike from the others families of hybrid carbon nanomaterials [9], the potential applications in biological/pharmaceutical field of carbon based nanomaterials- porphyrins appear still scarcely investigated, especially for J-aggregates self-assemblies as well as their intracellular trafficking, therapeutic and imaging properties. In the literature, it was observed that hybrids nanomaterials based on porphyrinoids $[24,63]$ were prepared at $\mathrm{pH}$ different from physiological conditions, and then treated with cells. In this context, future work will be devoted to studying the biocompatibility and cellular uptake of our hybrid MWCNTs/J-aggregates supramolecular systems. With these perspectives in mind, this research could lay the groundwork for the incoming biological assessment of MWCNT-EPA/TPPS J-aggregates.

\section{Conclusions}

MWCNTs can be easily functionalized by covalently introducing pendant amino-groups on their surface. In this paper we used ethylenediamine (EDA) and tetraethylenepentamine (EPA), which after coupling with carboxylic groups on the exterior walls, led to one and four protonable amino groups for chain, respectively. Under mild acidic conditions, the diacid form of TPPS is able to electrostatically bind to the surface and eventually aggregate. In line with our previous investigations on the ability of polyamines to trigger the aggregation of TPPS, the presence of only one pendant amino group (EDA) is not enough to induce the formation of TPPS J-aggregates, whatever the mixing protocol. On the other hand, when EPA functionality is present, these species are effective to generate stable MWCNT-EPA/TPPS J-aggregates nanohybrids and their general spectroscopic features are 
rather independent on the mixing protocol. A similar behavior was observed in solutions mimicking physiological medium $(\mathrm{NaCl} \cong 0.15 \mathrm{M})$, whereby stable nanohybrids were also obtained. These systems exhibit remarkable optical features, and in this perspective could be considered for potential applications in phototherapy (by irradiating on extinction bands at $491 \mathrm{~nm}$ and/or at $709 \mathrm{~nm}$ ) and/or bio-imaging (by exploiting the fluorescent emission band at $716 \mathrm{~nm}$ ). In this respect, this class of amine-modified MWCNTs could be investigated as carriers of J-aggregates in biological environment. All these optical and structural properties make MWCNT-EPA/TPPS J-aggregates appealing for further considerations in theranostic.

Supplementary Materials: The following are available online at http://www.mdpi.com/2079-4991/10/4/669/s1, Figure S1: TEM image of pristine MWCNTs; Figure S2: TEM images of MWCNT-EPA/TPPS J-aggregates; Figure S3: STEM of MWCNT-EPA/TPPS J-aggregates; Figure S4: UV-Vis spectra of an aqueous solution of TPPS J-aggregates/MWCNT-EPA (PF protocol) and MWCNT-EPA TPPS J-aggregates (PL protocol); Figure S5: CD spectra of an aqueous solution of TPPS J-aggregates/MWCNT-EPA (PF protocol) and MWCNT-EPA/TPPS J-aggregates (PL protocol); Figure S6: TEM images of TPPS J-aggregates/MWCNT-EPA (PF protocol).

Author Contributions: Conceptualization, A.M., M.A.C., A.R. and L.M.S.; investigation, M.T., A.M., A.P. and A.C.; data curation, M.T., A.M. and A.P.; writing—original draft preparation, M.T., A.M. and L.M.S.; writing一review and editing, A.M., R.Z., M.A.C. and A.R.; visualization, R.Z., M.A.C. and A.R.; Supervision, L.M.S. All authors discussed the results and commented on the manuscript. All authors have read and agreed to the published version of the manuscript.

Funding: This research was funded by CNR (Project ISMN-CNR: Materials and Dispositives for Health and Life Quality) for financial support.

Acknowledgments: We are grateful to Yanqui Zhu and Hong Chang (University of Exeter) for kind assistance with TGA, TEM and STEM analyses.

Conflicts of Interest: The authors declare no conflict of interest.

\section{References}

1. Poudel, Y.R.; Li, W. Synthesis, properties, and applications of carbon nanotubes filled with foreign materials: A review. Mater. Today Phys. 2018, 7, 7-34. [CrossRef]

2. Marchesan, S.; Kostarelos, K.; Bianco, A.; Prato, M. The winding road for carbon nanotubes in nanomedicine. Mater. Today 2015, 18, 12-19. [CrossRef]

3. Negri, V.; Pacheco-Torres, J.; Calle, D.; López-Larrubia, P. Carbon Nanotubes in Biomedicine. Top. Curr. Chem. 2020, 378, 15. [CrossRef] [PubMed]

4. Costa, P.M.; Bourgognon, M.; Wang, J.T.W.; Al-Jamal, K.T. Functionalised carbon nanotubes: From intracellular uptake and cell-related toxicity to systemic brain delivery. J. Control. Release 2016, 241, 200-219. [CrossRef] [PubMed]

5. Aoki, K.; Saito, N. Biocompatibility and Carcinogenicity of Carbon Nanotubes as Biomaterials. Nanomaterials 2020, 10, 264. [CrossRef] [PubMed]

6. Battigelli, A.; Ménard-Moyon, C.; Da Ros, T.; Prato, M.; Bianco, A. Endowing carbon nanotubes with biological and biomedical properties by chemical modifications. Adv. Drug Deliv. Rev. 2013, 65, 1899-1920. [CrossRef]

7. Iannazzo, D.; Mazzaglia, A.; Scala, A.; Pistone, A.; Galvagno, S.; Lanza, M.; Riccucci, C.; Ingo, G.M.; Colao, I.; Sciortino, M.T.; et al. $\beta$-Cyclodextrin-grafted on multiwalled carbon nanotubes as versatile nanoplatform for entrapment of guanine-based drugs. Colloids Surf. B Biointerfaces 2014, 123, 264-270. [CrossRef]

8. Mazzaglia, A.; Scala, A.; Sortino, G.; Zagami, R.; Zhu, Y.; Sciortino, M.T.; Pennisi, R.; Pizzo, M.M.; Neri, G.; Grassi, G.; et al. Intracellular trafficking and therapeutic outcome of multiwalled carbon nanotubes modified with cyclodextrins and polyethylenimine. Colloids Surf. B Biointerfaces 2018, 163, 55-63. [CrossRef]

9. Piperno, A.; Scala, A.; Mazzaglia, A.; Neri, G.; Pennisi, R.; Sciortino, M.T.; Grassi, G. Cellular Signaling Pathways Activated by Functional Graphene Nanomaterials. Int. J. Mol. Sci. 2018, 19, 3365. [CrossRef]

10. Piperno, A.; Mazzaglia, A.; Scala, A.; Pennisi, R.; Zagami, R.; Neri, G.; Torcasio, S.M.; Rosmini, C.; Mineo, P.G.; Potara, M.; et al. Casting Light on Intracellular Tracking of a New Functional Graphene-Based MicroRNA Delivery System by FLIM and Raman Imaging. ACS Appl. Mater. Interfaces 2019, 11, 46101-46111. [CrossRef] 
11. Vialla, F.; Delport, G.; Chassagneux, Y.; Roussignol, P.; Lauret, J.S.; Voisin, C. Diameter-selective non-covalent functionalization of carbon nanotubes with porphyrin monomers. Nanoscale 2016, 8, 2326-2332. [CrossRef] [PubMed]

12. Sprafke, J.K.; Stranks, S.D.; Warner, J.H.; Nicholas, R.J.; Anderson, H.L. Noncovalent Binding of Carbon Nanotubes by Porphyrin Oligomers. Angew. Chem. Int. Ed. 2011, 50, 2313-2316. [CrossRef] [PubMed]

13. Vizuete, M.; Gómez-Escalonilla, M.J.; Fierro, J.L.G.; Atienzar, P.; García, H.; Langa, F. Double-Wall Carbon Nanotube-Porphyrin Supramolecular Hybrid: Synthesis and Photophysical Studies. ChemPhysChem 2014, 15, 100-108. [CrossRef] [PubMed]

14. Magadur, G.; Lauret, J.-S.; Alain-Rizzo, V.; Voisin, C.; Roussignol, P.; Deleporte, E.; Delaire, J.A. Excitation Transfer in Functionalized Carbon Nanotubes. ChemPhysChem 2008, 9, 1250-1253. [CrossRef] [PubMed]

15. Zhang, H.; Bork, M.A.; Riedy, K.J.; McMillin, D.R.; Choi, J.H. Understanding Photophysical Interactions of Semiconducting Carbon Nanotubes with Porphyrin Chromophores. J. Phys. Chem. C 2014, 118, 11612-11619. [CrossRef]

16. Hasobe, T.; Fukuzumi, S.; Kamat, P.V. Ordered Assembly of Protonated Porphyrin Driven by Single-Wall Carbon Nanotubes. J- and H-Aggregates to Nanorods. J. Am. Chem. Soc. 2005, 127, 11884-11885. [CrossRef]

17. Aurisicchio, C.; Marega, R.; Corvaglia, V.; Mohanraj, J.; Delamare, R.; Vlad, D.A.; Kusko, C.; Dutu, C.A.; Minoia, A.; Deshayes, G.; et al. CNTs in Optoelectronic Devices: New Structural and Photophysical Insights on Porphyrin-DWCNTs Hybrid Materials. Adv. Funct. Mater. 2012, 22, 3209-3222. [CrossRef]

18. Devaramani, S.; Shinger, M.I.; Ma, X.; Yao, M.; Zhang, S.; Qin, D.; Lu, X. Porphyrin aggregates decorated MWCNT film for solar light harvesting: Influence of J- and H-aggregation on the charge recombination resistance, photocatalysis, and photoinduced charge transfer kinetics. Phys. Chem. Chem. Phys. 2017, 19, 18232-18242. [CrossRef]

19. Lutsyk, P.; Piryatinski, Y.; Shandura, M.; AlAraimi, M.; Tesa, M.; Arnaoutakis, G.E.; Melvin, A.A.; Kachkovsky, O.; Verbitsky, A.; Rozhin, A. Self-Assembly for Two Types of J-Aggregates: Cis-Isomers of Dye on the Carbon Nanotube Surface and Free Aggregates of Dye trans-Isomers. J. Phys. Chem. C 2019, 123, 19903-19911. [CrossRef]

20. Würthner, F.; Kaiser, T.E.; Saha-Möller, C.R. J-Aggregates: From Serendipitous Discovery to Supramolecular Engineering of Functional Dye Materials. Angew. Chem. Int. Ed. 2011, 50, 3376-3410. [CrossRef]

21. Song, X.; Zhang, R.; Liang, C.; Chen, Q.; Gong, H.; Liu, Z. Nano-assemblies of J-aggregates based on a NIR dye as a multifunctional drug carrier for combination cancer therapy. Biomaterials 2015, 57, 84-92. [CrossRef] [PubMed]

22. Miranda, D.; Huang, H.; Kang, H.; Zhan, Y.; Wang, D.; Zhou, Y.; Geng, J.; Kilian, H.I.; Stiles, W.; Razi, A.; et al. Highly-Soluble Cyanine J-aggregates Entrapped by Liposomes for In Vivo Optical Imaging around $930 \mathrm{~nm}$. Theranostics 2019, 9, 381-390. [CrossRef] [PubMed]

23. Shakiba, M.; Ng, K.K.; Huynh, E.; Chan, H.; Charron, D.M.; Chen, J.; Muhanna, N.; Foster, F.S.; Wilson, B.C.; Zheng, G. Stable J-aggregation enabled dual photoacoustic and fluorescence nanoparticles for intraoperative cancer imaging. Nanoscale 2016, 8, 12618-12625. [CrossRef] [PubMed]

24. Liu, W.-J.; Zhang, D.; Li, L.-L.; Qiao, Z.-Y.; Zhang, J.-C.; Zhao, Y.-X.; Qi, G.-B.; Wan, D.; Pan, J.; Wang, H. In Situ Construction and Characterization of Chlorin-Based Supramolecular Aggregates in Tumor Cells. ACS Appl. Mater. Interfaces 2016, 8, 22875-22883. [CrossRef]

25. Cheng, M.H.Y.; Harmatys, K.M.; Charron, D.M.; Chen, J.; Zheng, G. Stable J-Aggregation of an aza-BODIPY-Lipid in a Liposome for Optical Cancer Imaging. Angew. Chem. Int. Ed. 2019, 58, 13394-13399. [CrossRef]

26. Gandini, S.C.M.; Gelamo, E.L.; Itri, R.; Tabak, M. Small angle X-ray scattering study of meso-tetrakis (4-sulfonatophenyl) porphyrin in aqueous solution: A self-aggregation model. Biophys. J. 2003, 85, 1259-1268. [CrossRef]

27. Collini, E.; Ferrante, C.; Bozio, R.; Lodi, A.; Ponterini, G. Large third-order nonlinear optical response of porphyrin J-aggregates oriented in self-assembled thin films. J. Mater. Chem. 2006, 16, 1573-1578. [CrossRef]

28. Collini, E.; Ferrante, C.; Bozio, R. Strong Enhancement of the Two-Photon Absorption of Tetrakis(4-sulfonatophenyl)porphyrin Diacid in Water upon Aggregation. J. Phys. Chem. B 2005, 109, 2-5. [CrossRef]

29. Castriciano, M.A.; Donato, M.G.; Villari, V.; Micali, N.; Romeo, A.; Scolaro, L.M. Surfactant-like behavior of short-chain alcohols in porphyrin aggregation. J. Phys. Chem. B 2009, 113, 11173-11178. [CrossRef] 
30. Zagami, R.; Castriciano, M.A.; Romeo, A.; Trapani, M.; Pedicini, R.; Monsù Scolaro, L. Tuning supramolecular chirality in nano and mesoscopic porphyrin J-aggregates. Dyes Pigments 2017, 142, 255-261. [CrossRef]

31. Scolaro, L.M.; Romeo, A.; Castriciano, M.A.; Micali, N. Unusual optical properties of porphyrin fractal J-aggregates. Chem. Commun. 2005, 3018-3020. [CrossRef]

32. Villari, V.; Fazio, B.; De Luca, G.; Trapani, M.; Romeo, A.; Scolaro, L.M.; Castriciano, M.A.; Mazzaglia, A.; Micali, N. Scattering enhancement in colloidal metal-organic composite aggregates. Colloids Surf. A Physicochem. Eng. Asp. 2012, 413, 13-16. [CrossRef]

33. Villari, V.; Fazio, B.; Micali, N.; De Luca, G.; Corsaro, C.; Romeo, A.; Scolaro, L.M.; Castriciano, M.A.; Mazzaglia, A. Light scattering enhancement in porphyrin nanocomposites. In Proceedings of the International School of Physics Enrico Fermi; Mallamace, F., Stanley, H., Eds.; IOS: Amsterdam, The Netherlands; SIF: Bologna, Italy, 2012; pp. 335-340. [CrossRef]

34. Castriciano, M.A.; Romeo, A.; Scolaro, L.M. Aggregation of meso-tetrakis(4-sulfonatophenyl)porphyrin on polyethyleneimine in aqueous solutions and on a glass surface. J. Porphyr. Phthalocyanines 2002, 6, 431-438. [CrossRef]

35. Micali, N.; Villari, V.; Romeo, A.; Castriciano, M.A.; Scolaro, L.M. Evidence of the early stage of porphyrin aggregation by enhanced Raman scattering and fluorescence spectroscopy. Phys. Rev. E Stat. Nonlinear Soft Matter Phys. 2007, 76. [CrossRef] [PubMed]

36. Castriciano, M.A.; Trapani, M.; Romeo, A.; Depalo, N.; Rizzi, F.; Fanizza, E.; Patanè, S.; Monsù Scolaro, L. Influence of Magnetic Micelles on Assembly and Deposition of Porphyrin J-Aggregates. Nanomaterials 2020, 10, 187. [CrossRef] [PubMed]

37. Trapani, M.; Castriciano, M.A.; Romeo, A.; De Luca, G.; Machado, N.; Howes, B.D.; Smulevich, G.; Scolaro, L.M. Nanohybrid Assemblies of Porphyrin and Au-10 Cluster Nanoparticles. Nanomaterials 2019, 9. [CrossRef] [PubMed]

38. Trapani, M.; De Luca, G.; Romeo, A.; Castriciano, M.A.; Scolaro, L.M. Spectroscopic investigation on porphyrins nano-assemblies onto gold nanorods. Spectrochim. Acta Part A Mol. Biomol. Spectrosc. 2017, 173, 343-349. [CrossRef]

39. Castriciano, M.A.; Leone, N.; Cardiano, P.; Manickam, S.; Scolaro, L.M.; Lo Schiavo, S. A new supramolecular polyhedral oligomeric silsesquioxanes (POSS)-porphyrin nanohybrid: Synthesis and spectroscopic characterization. J. Mater. Chem. C 2013, 1, 4746-4753. [CrossRef]

40. Villari, V.; Mazzaglia, A.; Trapani, M.; Castriciano, M.A.; De Luca, G.; Romeo, A.; Scolaro, L.M.; Micali, N. Optical enhancement and structural properties of a hybrid organic-inorganic ternary nanocomposite. J. Phys. Chem. C 2011, 115, 5435-5439. [CrossRef]

41. Hollingsworth, J.V.; Richard, A.J.; Vicente, M.G.H.; Russo, P.S. Characterization of the Self-Assembly of meso-Tetra(4-sulfonatophenyl)porphyrin (H2TPPS4-) in Aqueous Solutions. Biomacromolecules 2012, 13, 60-72. [CrossRef]

42. Castriciano, M.A.; Romeo, A.; Villari, V.; Micali, N.; Scolaro, L.M. Structural rearrangements in 5,10,15,20-tetrakis(4-sulfonatophenyl)porphyrin J-aggregates under strongly acidic conditions. J. Phys. Chem. B 2003, 107, 8765-8771. [CrossRef]

43. Romeo, A.; Castriciano, M.A.; Occhiuto, I.; Zagami, R.; Pasternack, R.F.; Scolaro, L.M. Kinetic control of chirality in porphyrin J-aggregates. J. Am. Chem. Soc. 2014, 136, 40-43. [CrossRef] [PubMed]

44. Occhiuto, I.G.; Zagami, R.; Trapani, M.; Bolzonello, L.; Romeo, A.; Castriciano, M.A.; Collini, E.; Monsù Scolaro, L. The role of counter-anions in the kinetics and chirality of porphyrin J-aggregates. Chem. Commun. 2016, 52, 11520-11523. [CrossRef] [PubMed]

45. Occhiuto, I.; De Luca, G.; Trapani, M.; Scolaro, L.M.; Pasternack, R.F. Peripheral Stepwise Degradation of a Porphyrin J-Aggregate. Inorg. Chem. 2012, 51, 10074-10076. [CrossRef]

46. Trapani, M.; Occhiuto, I.G.; Zagami, R.; De Luca, G.; Castriciano, M.A.; Romeo, A.; Scolaro, L.M.; Pasternack, R.F. Mechanism for Copper(II)-Mediated Disaggregation of a Porphyrin J-Aggregate. ACS Omega 2018, 3, 18843-18848. [CrossRef]

47. Liu, R.; Tang, J.; Xu, Y.; Zhou, Y.; Dai, Z. Nano-sized Indocyanine Green J-aggregate as a One-component Theranostic Agent. Nanotheranostics 2017, 1, 430-439. [CrossRef]

48. Qu, K.; Xu, H.; Zhao, C.; Ren, J.; Qu, X. Amine-linker length dependent electron transfer between porphyrins and covalent amino-modified single-walled carbon nanotubes. RSC Adv. 2011, 1, 632-639. [CrossRef] 
49. Chen, J.; Collier, C.P. Noncovalent Functionalization of Single-Walled Carbon Nanotubes with Water-Soluble Porphyrins. J. Phys. Chem. B 2005, 109, 7605-7609. [CrossRef]

50. Cardiano, P.; Fazio, E.; Lazzara, G.; Manickam, S.; Milioto, S.; Neri, F.; Mineo, P.G.; Piperno, A.; Lo Schiavo, S. Highly untangled multiwalled carbon nanotube@polyhedral oligomeric silsesquioxane ionic hybrids: Synthesis, characterization and nonlinear optical properties. Carbon 2015, 86, 325-337. [CrossRef]

51. Kaiser, E.; Colescott, R.L.; Bossinger, C.D.; Cook, P.I. Color test for detection of free terminal amino groups in the solid-phase synthesis of peptides. Anal. Biochem. 1970, 34, 595-598. [CrossRef]

52. Ménard-Moyon, C.; Fabbro, C.; Prato, M.; Bianco, A. One-Pot Triple Functionalization of Carbon Nanotubes. Chem. Eur. J. 2011, 17, 3222-3227. [CrossRef] [PubMed]

53. Romeo, A.; Angela Castriciano, M.; Scolaro, L.M. Spectroscopic and kinetic investigations on porphyrin J-aggregates induced by polyamines. J. Porphyr. Phthalocyanines 2010, 14, 713-721. [CrossRef]

54. Pasternack, R.F.; Collings, P.J. Resonance Light-Scattering-A New Technique for Studying Chromophore Aggregation. Science 1995, 269, 935-939. [CrossRef] [PubMed]

55. Tuci, G.; Vinattieri, C.; Luconi, L.; Ceppatelli, M.; Cicchi, S.; Brandi, A.; Filippi, J.; Melucci, M.; Giambastiani, G. "Click" on Tubes: A Versatile Approach towards Multimodal Functionalization of SWCNTs. Chem. Eur. J. 2012, 18, 8454-8463. [CrossRef] [PubMed]

56. Iannazzo, D.; Piperno, A.; Ferlazzo, A.; Pistone, A.; Milone, C.; Lanza, M.; Cimino, F.; Speciale, A.; Trombetta, D.; Saija, A.; et al. Functionalization of multi-walled carbon nanotubes with coumarin derivatives and their biological evaluation. Organ. Biomol. Chem. 2012, 10, 1025-1031. [CrossRef]

57. Grassi, G.; Scala, A.; Piperno, A.; Iannazzo, D.; Lanza, M.; Milone, C.; Pistone, A.; Galvagno, S. A facile and ecofriendly functionalization of multiwalled carbon nanotubes by an old mesoionic compound. Chem. Commun. 2012, 48, 6836-6838. [CrossRef]

58. Castriciano, M.A.; Carbone, A.; Saccà, A.; Donato, M.G.; Micali, N.; Romeo, A.; De Luca, G.; Scolaro, L.M. Optical and sensing features of TPPS4 J-aggregates embedded in Nafion®membranes: Influence of casting solvents. J. Mater. Chem. 2010, 20, 2882-2886. [CrossRef]

59. Maiti, N.C.; Mazumdar, S.; Periasamy, N. J- and H-aggregates of porphyrins with surfactants: Fluorescence, stopped flow and electron microscopy studies. J. Porphyr. Phthalocyanines 1998, 2, 369-376. [CrossRef]

60. Maiti, N.C.; Ravikanth, M.; Mazumdar, S.; Periasamy, N. Fluorescence Dynamics of Noncovalently Linked Porphyrin Dimers, and Aggregates. J. Phys. Chem. B 1995, 99, 17192-17197. [CrossRef]

61. Micali, N.; Villari, V.; Scolaro, L.M.; Romeo, A.; Castriciano, M.A. Light scattering enhancement in an aqueous solution of spermine-induced fractal J-aggregate composite. Phys. Rev. E Stat. Nonlinear Soft Matter Phys. 2005, 72. [CrossRef]

62. Micali, N.; Villari, V.; Castriciano, M.A.; Romeo, A.; Scolaro, L.M. From fractal to nanorod porphyrin J-aggregates. concentration-induced tuning of the aggregate size. J. Phys. Chem. B 2006, 110, 8289-8295. [CrossRef] [PubMed]

63. Trapani, M.; Romeo, A.; Parisi, T.; Sciortino, M.T.; Patanè, S.; Villari, V.; Mazzaglia, A. Supramolecular hybrid assemblies based on gold nanoparticles, amphiphilic cyclodextrin and porphyrins with combined phototherapeutic action. RSC Adv. 2013, 3, 5607-5614. [CrossRef]

(C) 2020 by the authors. Licensee MDPI, Basel, Switzerland. This article is an open access article distributed under the terms and conditions of the Creative Commons Attribution (CC BY) license (http://creativecommons.org/licenses/by/4.0/). 